\title{
Assessment of the Effectiveness of Two Coordinated Systems: SVC-PSS and STATCOM-PSS for Improving Transient Stability of Power System
}

\author{
Tran Thi Ngoat and Le Ngoc Giang
}

\begin{abstract}
The power system stabilizer (PSS) is a control device provides a maximum power transfer and optimal power system stability. PSS has been widely used to damp electromechanical oscillations that occur in power systems due to disturbances. If no adequate damping is available, the oscillation will increase result in instability case. Shunt static var compensator (SVC) and Static Synchronous Compensator (STATCOM) is also used to improve system stability. This paper focus on the significant of SVC-PSS and STATCOMPSS to improve the transient stability of power system in various abnormal condition. This paper shows the simulation result of model for different fault condition with PSS and without PSS, with SVC and without SVC, with STATCOM and without STATCOM, and show how the Statcom and SVC help to improve the stability when PSS is fail to maintain the stability.
\end{abstract}

Index Terms-STATCOM, SVC, PSS, power system.

\section{INTRODUCTION}

For many years, one of the major interests that power system should fulfill is satisfying sufficient conditions of stability. This interest is becoming a serious concern. Indeed, in the one hand, the energy market evolution while the weakness of the transmission net due to financial difficulties and high costs of rights, don't make viable the construction of new lines and hence the higher loading of existing transmission lines. In the other hand, if the power system is subject to a several disturbance such as short circuits. Disequilibrium between mechanical and electrical power can be instituted, this can affect rotor speed variations and can lead to a partial or total outage. It is well established that power system stabilizer is the first measure that has been used to improve damping oscillations of power system during electromechanical transients. Recently, researchers demonstrate that FACTS devices offer an alternative mean to mitigate power system oscillations.

Stability of this system needs to be maintained even when subjected to large low-probability disturbances so that the electricity can be supplied to consumers with high reliability. Certain system disturbances may cause loss of synchronism between a generator and the rest of the utility system, or between interconnected power systems of neighboring utilities [1]. Various control methods and controllers have been developed over time that has been used for this purpose.

Manuscript received December 20, 2012; revised February 22, 2013.

T. T. Ngoat and L. N. Giang are with the School of Electrical Engineering, Wuhan University, Wuhan 430072, China (e-mail: ngoat_hy@yahoo.com; lengocgianglinh@gmail.com).
Since 1960s, low frequency oscillations have been observed when large power systems are interconnected by relatively weak tie lines. These oscillations may sustain and grow to cause system separation if no adequate damping is available [2], [3]. Nowadays, the power system stabilizer (PSS) is widely used by power system utilities. Generally, it is important to recognize that machine parameters change with loading make the machine behavior quite different at different operating conditions. Since these parameters change in a rather complex manner, a set of stabilizer parameters, which stabilizes the system under a certain operating condition, may no longer yield satisfactory results when there is a drastic change in power system operating conditions and configurations. Hence, SVC and STATCOM should provide some degree of robustness to the variations in system parameters, loading conditions, and configurations. In some case PSS are fail to maintain the stability of power system, so that are use the FACT device which give additional support to maintain the stability of power system. So we are show the effect of STATCOMPSS and SVC_PSS in this paper.

\section{SYSTEM MODEL}

This paper simulation of a common system model consists of two synchronous generators:

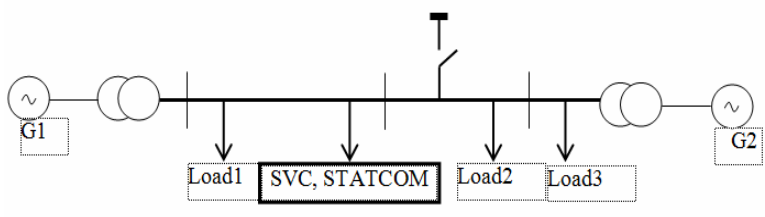

Fig. 1. System model

\section{A. Generator}

Fig.1 show the two-area system used in the study. The system consists of two different areas. Each area includes two generating units equipped with fast static exciters. All two generating units are represented by the same dynamic model.

Generation G1: Nominal power 1000MW, line-to-line voltage $13,8 \mathrm{kV}$, frequency $60 \mathrm{~Hz}$.

Generation G2: Nominal power 5000MW, line-to-line voltage $13,8 \mathrm{kV}$, frequency $60 \mathrm{~Hz}$.

\section{B. Transformer}

Three-phase transformer T1:1000MVA, 13.8 kV/500 Kv. Three-phase transformer T2: 5000MVA , $13.8 \mathrm{kV} / 500 \mathrm{Kv}$.

\section{Load}

Load1: Three-Phase Parallel RLC Load P=10 MW, $\mathrm{Q}_{\mathrm{L}}=$ 
$2 \mathrm{kVAr}, \mathrm{Q}_{\mathrm{C}}=4 \mathrm{kVAr}$.

Load2: Three-Phase Series RLC Load P=500 MW, $\mathrm{Q}_{\mathrm{L}}=$ $5 \mathrm{kVAr}, \mathrm{Q}_{\mathrm{C}}=1 \mathrm{kVAr}$.

Load3: Three-Phase Parallel RLC Load P= 4500 MW, Q $\mathrm{L}=3 \mathrm{kVAr}, \mathrm{Q}_{\mathrm{C}}=1 \mathrm{kVAr}$.

\section{SVC, STATCOM}

To maintain system stability after faults, the transmission line is shunt compensated at its center by a 200 Mvar static var compensator (SVC), or a 200 Mvar Static Synchronous Compensator (Statcom).SVC and STATCOM is two shunt device of the Flexible AC Transmission Systems (FACTS) family using power electronics to control power flow and improve transient stability on power grids. The SVC regulates voltage at its terminals by controlling the amount of reactive power injected into or absorbed from the power system. When system voltage is low, the SVC, STATCOM generates reactive power (SVC, STATCOM capacitive). When system voltage is high, it absorbs reactive power (SVC, STATCOM inductive).

SVC: The variation of reactive power is performed by switching three-phase capacitor banks and inductor banks connected on the secondary side of a coupling transformer. Each capacitor bank is switched on and off by three thyristor switches (Thyristor Switched Capacitor or TSC). Reactors are either switched on-off (Thyristor Switched Reactor or TSR) or phase-controlled (Thyristor Controlled Reactor or TCR)

[4]-

[6]

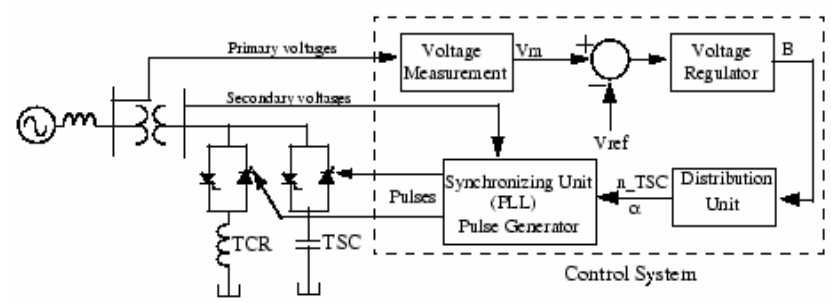

Fig. 2. Single-line diagram of an svc and its control system block diagram

STATCOM: The variation of reactive power is performed by means of a Voltage-Sourced Converter (VSC) connected on the secondary side of a coupling transformer. The VSC uses forced-commutated power electronic devices (GTOs, IGBTs or IGCTs) to synthesize a voltage V2 from a DC voltage source [7]-[9]. The principle of operation of the STATCOM is explained on the figure below showing the active and reactive power transfer between a source V1 and a source V2. In this figure, V1 represents the system voltage to be controlled and V2 is the voltage generated by the VSC[10].
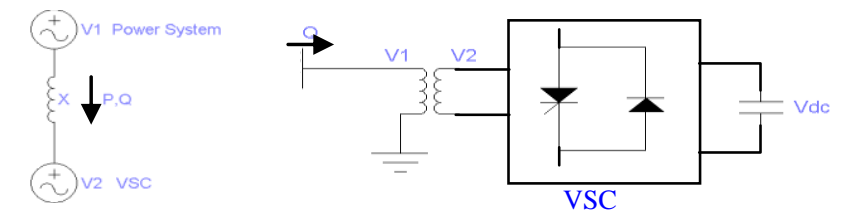

Fig. 3. Operating Principle of the STATCOM

$$
P=\frac{V_{1} V_{2} \sin \delta}{X} \quad Q=\frac{V_{1}\left(V_{1}-V_{2} \cos \delta\right)}{X}
$$

where:
$\mathrm{V} 1=$ line to line Voltage of source V1

$\mathrm{V} 2=$ line to line Voltage V2

$\mathrm{X}=$ Reactance of interconnection transformer and filter

$\delta=$ angle of $\mathrm{V} 1$ with respect to $\mathrm{V} 2$

\section{E. Fault Breaker block}

A Fault Breaker block is connected at bus B2. we will use it to program different types of faults on the $500 \mathrm{kV}$ system and observe the impact of the PSS and SVC, STATCOM on system stability.

\section{F. Power System Stabilizers (PSS)}

The power system stabilizer is a control device use to damp out low frequency oscillations [11]. Such modes are known as interarea or local modes. The parameters of the PSS are tuned on-line to suppress these modes. The design of the PSS is still made on the basis of a single machine infinite bus system (SMIB) system even though a considerable research is being done in designing PSS for a multimachine system with no significant results as several rotor oscillation frequencies have to be considered. The block diagram of the PSS used in real life is shown in Fig. 4.

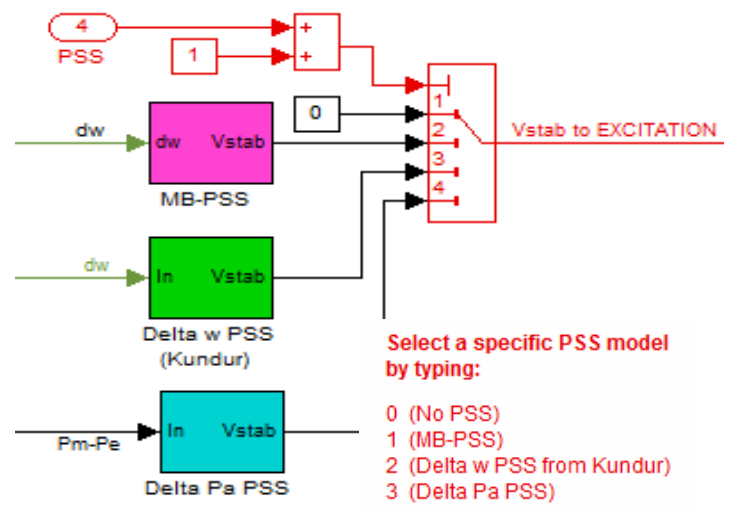

Fig. 4.The block diagram of the PSS

1) Multiband power system stabilizer (MB-PSS) Conceptual Representation

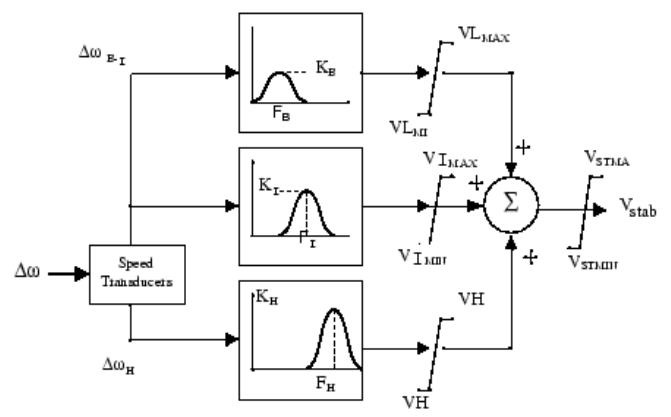

Fig. 5. MB-PSS

The disturbances occurring in a power system induce electromechanical oscillations of the electrical generators. These oscillations, also called power swings, must be effectively damped to maintain the system's stability. Electromechanical oscillations can be classified in four main categories:

Local oscillations: between a unit and the rest of the generating station and between the latter and the rest of the power system. Their frequencies typically range from 0.8 to 4.0 Hz.

Interplant oscillations: between two electrically close generation plants. Frequencies can vary from 1 to $2 \mathrm{~Hz}$. 
Interarea oscillations: between two major groups of generation plants. Frequencies are typically in a range of 0.2 to $0.8 \mathrm{~Hz}$.

Global oscillation: characterized by a common in-phase oscillation of all generators as found on an isolated system. The frequency of such a global mode is typically under 0.2 $\mathrm{Hz}$.

The MB-PSS structure is based on multiple working bands. Three separate bands are used, respectively dedicated to the low-, intermediate-, and high-frequency modes of oscillations: the low band is typically associated with the power system global mode, the intermediate with the interarea modes, and the high with the local modes.

Each of the three bands is made of a differential bandpass filter, a gain, and a limiter. The outputs of the three bands are summed and passed through a final limiter producing the stabilizer output $\mathrm{V}_{\text {stab. This }}$ signal then modulates the set point of the generator voltage regulator so as to improve the damping of the electromechanical oscillations.

To ensure robust damping, the MB-PSS should include a moderate phase advance at all frequencies of interest to compensate for the inherent lag between the field excitation and the electrical torque induced by the MB-PSS action.

\section{2) Generic Power System Stabilizer}

The Generic Power System Stabilizer (PSS) block can be used to add damping to the rotor oscillations of the synchronous machine by controlling its excitation. The disturbances occurring in a power system induce electromechanical oscillations of the electrical generators. These oscillations, also called power swings, must be effectively damped to maintain the system stability [12][14]. The output signal of the PSS is used as an additional input (vstab) to the Excitation System block. The PSS input signal can be either the machine speed deviation, dw, or its acceleration power, $\mathrm{Pa}=\mathrm{Pm}$ - Peo (difference between the mechanical power and the electrical power).

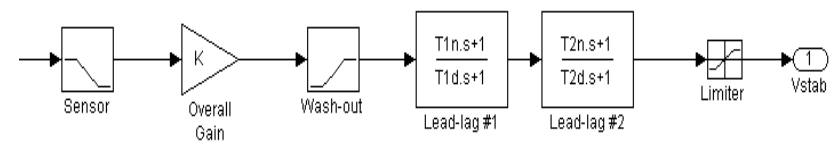

Fig. 6. Delta w PSS

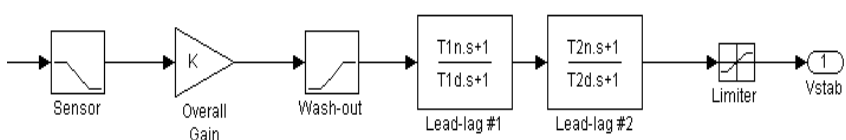

Fig. 7. Delta Pa PSS

\section{G. The Excitation Control}

The basic function of an exciter is to provide a dc source for field excitation of a synchronous generator. A control on exciter voltage results in controlling the field current, which, in turn, controls the generated voltage. When a synchronous generator is connected to a large system where the operating frequency and the terminal voltages are largely unaffected by generator, its excitation control causes its reactive power output to change. In older power plants, a dc generator, also called an exciter, was mounted on the main generator shaft. A control of the field excitation of the dc generator provided a controlled excitation source for the main generator. In contrast, modern stations employ either a brushless exciter (an inverted 3-phase alternator with a solid-state rectifier connecting the resulting dc source directly through the shaft to the field windings of the main generator) or a static exciter (the use of a station supply with static rectifiers) [15].

An excitation-control system employs a voltage controller to control the excitation voltage. This operation is typically recognized as an Automatic Voltage Regulator (AVR), Fig. 8.

Because an excitation control operates quickly, several stabilizing and protective signals are invariably added to the basic voltage regulator. A Power-System Stabilizer (PSS) is implemented by adding auxiliary damping signals derived from the shaft speed, or the terminal frequency. Fig.9 shows the functionality of an excitation-control system [16], [17].

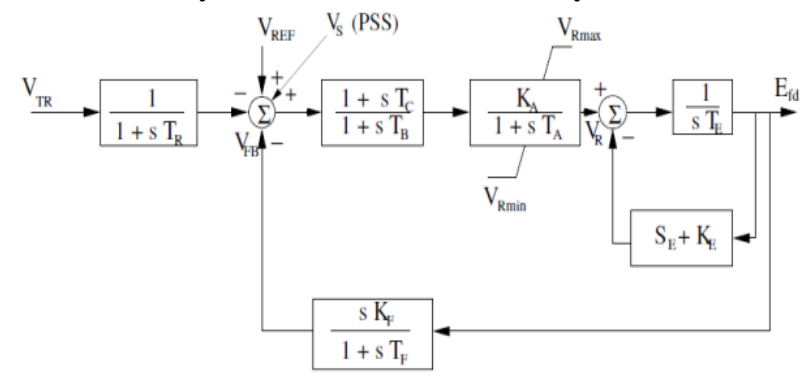

Fig. 8. AVR and exciter model for synchronous generator

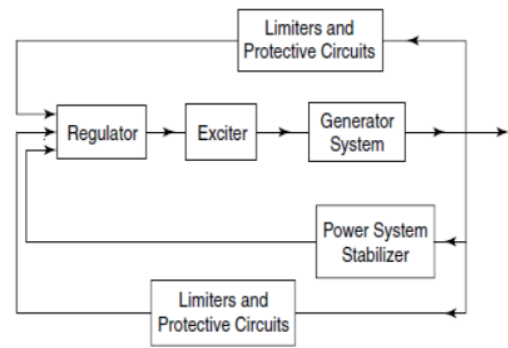

Fig. 9. A conceptual block diagram of a modern excitation controller

\section{Simulation Result}

\section{A. Without PSS, SVC, STATCOM}

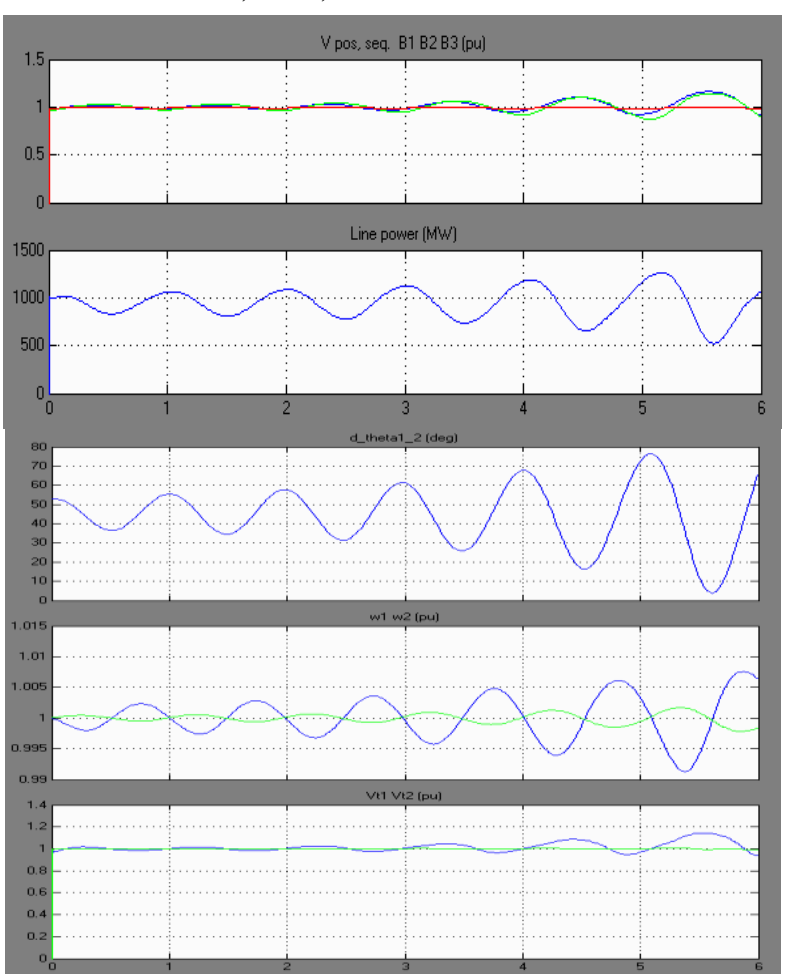

Fig. 10. Response of the system without PSS,SVC,STATCOM 


\section{B. With PSS without SVC, STATCOM}

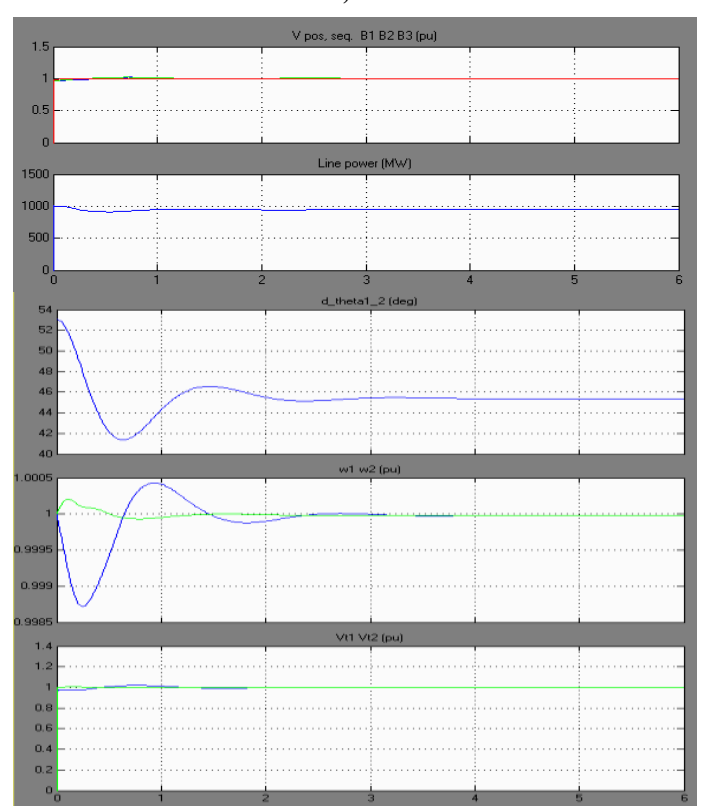

Fig. 11. Response of the system with PSS without SVC, STATCOM

\section{Single-Phase Fault, Impact of PSS -No SVC,} STATCOM

Fault applied at $\mathrm{t}=2 \mathrm{~s}$ and cleared at $\mathrm{t}=2.1 \mathrm{~s}$. Start the simulation and observe signals on the Machines scope. For this type of fault the system is stable without SVC. After fault clearing, the $0.6 \mathrm{~Hz}$ oscillation is quickly damped. This oscillation mode is typical of interarea oscillations in a large power system. First trace on the Machines scope shows the rotor angle difference d_theta1_2 between the two machines. Power transfer is maximum when this angle reaches 90 degrees. This signal is a good indication of system stability. If d_theta1_2 exceeds 90 degrees for too long a period of time, the machines will loose synchronism and the system goes unstable. Second trace shows the machine speeds. Notice that machine 1 speed increases during the fault because during that period its electrical power is lower than its mechanical power. By simulating over a long period of time (6 seconds) we will also notice that the machine speeds oscillate together at a low frequency $(0.025 \mathrm{~Hz})$ after fault clearing.

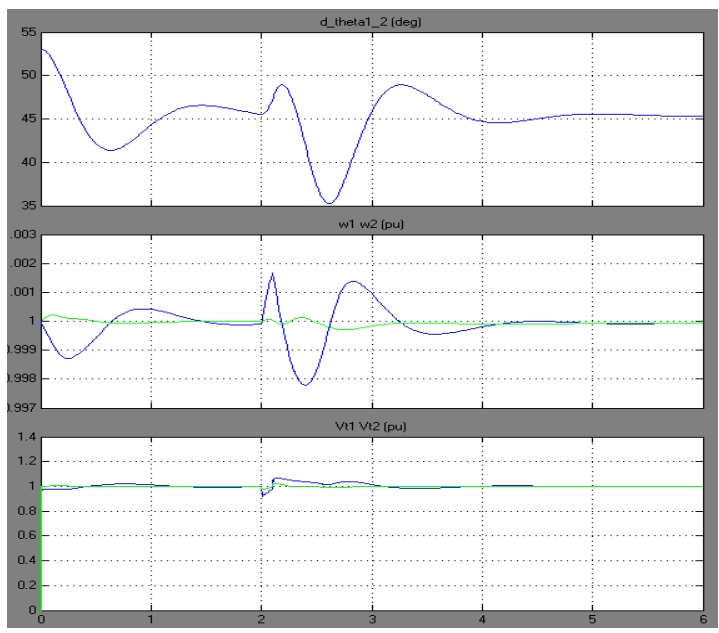

Fig. 12. Response of the system when Single-Phase Fault, with PSS without SVC, STATCOM

\section{Three-Phase Fault, Impact of PSS-SVC, PSS- STATCOM}

We will now apply a 3-phase fault and observe the impact of the SVC for stabilizing the network during.

First put the two PSS (Generic Pa type) in service. Reprogram the Fault Breaker block to apply a 3-phase-toground fault. Verify that the SVC is in fixed susceptance mode with Bref $=0$.

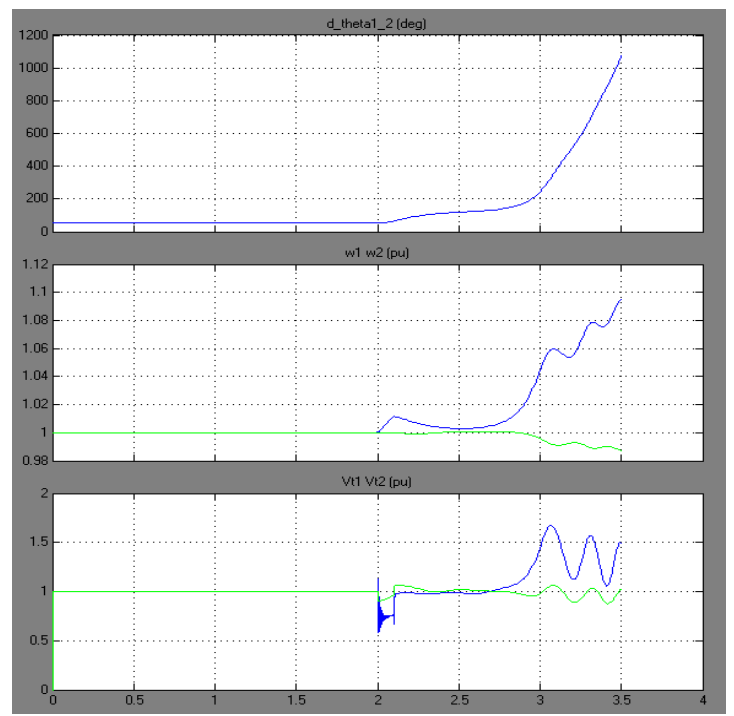

Fig. 13. Response of the system when Three-Phase Fault, with PSS without SVC, STATCOM

By looking at the d_theta1_2 signal, we should observe that the two machines quickly fall out of synchronism after fault clearing.

Change the SVC, STATCOM mode of operation to Voltage regulation. The SVC, STATCOM will now try to support the voltage by injecting reactive power on the line when the voltage is lower than the reference voltage (1.009 $\mathrm{pu})$. The chosen SVC, STATCOM reference voltage corresponds to the bus voltage with the SVC, STATCOM out of service. In steady state the SVC, STATCOM will therefore be floating and waiting for voltage compensation when voltage departs from its reference set point.

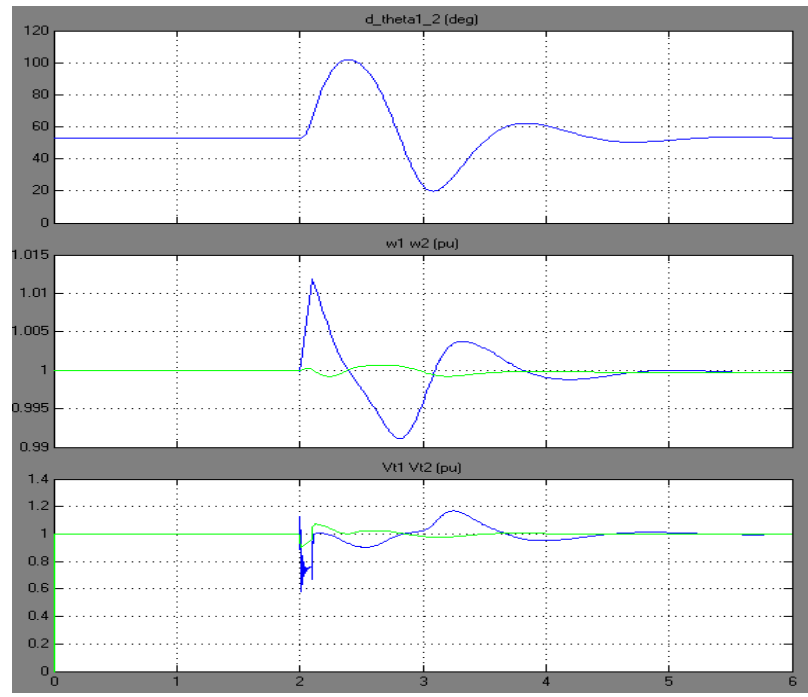

Fig. 14. Response of the system when Three-Phase Fault, with MB-PSS, with STATCOM 
From the simulation, using PSS we can stabilize our system up to certain limit and maintain the synchronism between he inter connected area and protect the whole power system from cascade tripping which is very serious matter. We can also say that only using PSS we cannot maintain stability but in some cases or condition it is equire using other devices to maintain stability. Nowadays SVC, STATCOM are widely use in system or compensation of reactive power demand and help to maintain system stability in some transient condition.

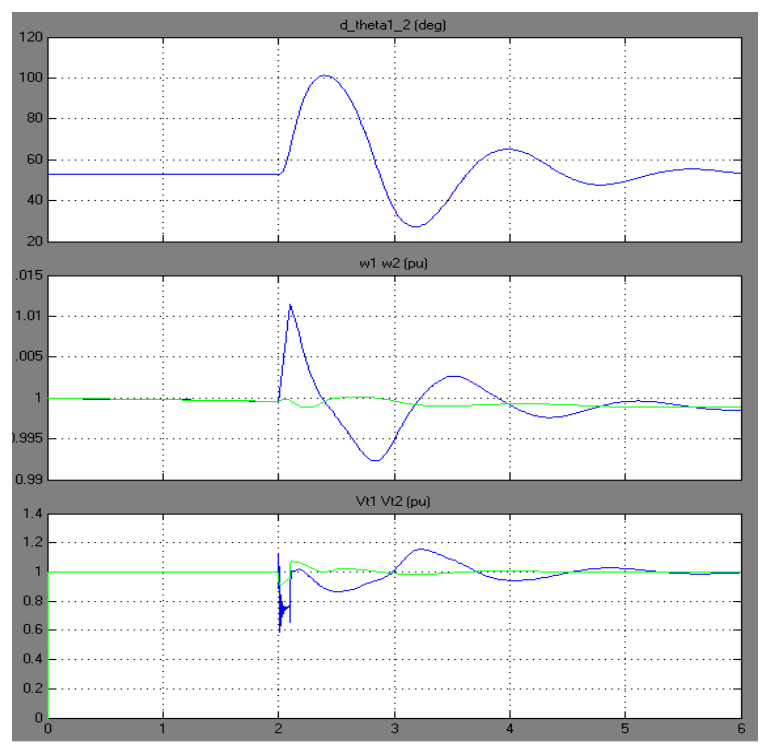

Fig. 16. Response of the system when Three-Phase Fault, with MB-PSS ,with SVC

\section{OBSERVATION TABLE}

TABLE I: SINGLE LINE TO GROUND

\begin{tabular}{|c|c|c|c|c|c|c|c|c|c|}
\hline & \multicolumn{3}{|c|}{ MB-PSS } & \multicolumn{3}{|c|}{ Delta W PSS } & \multicolumn{3}{|c|}{ Delta Pa PSS } \\
\hline & PSS & $\begin{array}{l}\text { SVC } \\
\text { PSS }\end{array}$ & \begin{tabular}{|c|} 
TATCOM \\
PSS \\
\end{tabular} & PSS & \begin{tabular}{|l|} 
SVC \\
PSS
\end{tabular} & \begin{tabular}{|c|} 
TATCOM \\
PSS \\
\end{tabular} & \begin{tabular}{|l|} 
PSS \\
\end{tabular} & SVC PSS & \begin{tabular}{|c|} 
TATCOM \\
PSS \\
\end{tabular} \\
\hline $\begin{array}{c}\text { Stable } \\
\text { time (s) }\end{array}$ & 5.5 & 4.4 & 4 & 3.8 & 3 & 2.5 & 7.5 & 6.5 & 7 \\
\hline $\begin{array}{c}\text { Angle } \\
\text { deviation } \\
\text { in degree }\end{array}$ & 52.5 & 52.8 & 52.9 & 52.5 & 52.9 & 52.9 & 52.5 & 52.8 & 52.8 \\
\hline
\end{tabular}

TABLE II: THREE LINE TO GROUND

\begin{tabular}{|c|c|c|c|c|c|c|c|c|c|}
\hline & \multicolumn{3}{|c|}{ MB-PSS } & \multicolumn{3}{|c|}{ Delta W PSS } & \multicolumn{3}{|c|}{ Delta Pa PSS } \\
\hline & PSS & $\begin{array}{l}\text { SVC } \\
\text { PSS }\end{array}$ & $\begin{array}{l}\text { TATCOM } \\
\text { PSS }\end{array}$ & \begin{tabular}{|l|} 
PSS \\
\end{tabular} & $\begin{array}{l}\text { SvC } \\
\text { PSS }\end{array}$ & $\begin{array}{l}\text { TATCOM } \\
\text { PSS }\end{array}$ & PSS & svc Pss & $\begin{array}{l}\text { TATCOM } \\
\text { PSS }\end{array}$ \\
\hline $\begin{array}{c}\text { Stable } \\
\text { time (s) }\end{array}$ & \begin{tabular}{|c|} 
Unstable \\
affer \\
$1.5 \mathrm{~s}$ \\
\end{tabular} & 4.9 & 3.5 & 5 & 4.6 & 4 & $\begin{array}{c}\begin{array}{c}\text { Unstable } \\
\text { after } \\
1.4 \mathrm{~s}\end{array} \\
\end{array}$ & 6.6 & 6.2 \\
\hline $\begin{array}{c}\text { Angle } \\
\text { deviation } \\
\text { in degree }\end{array}$ & \begin{tabular}{|c|} 
Above \\
1080
\end{tabular} & 53 & 52.8 & 52.5 & 53 & 52.9 & $\begin{array}{l}\text { Above } \\
1080\end{array}$ & 53 & 52.9 \\
\hline
\end{tabular}

From here, we show that if all three phase transient fault, Without SVC and STATCOM, PSS can't be able to maintain stability. In application of SVC, STATCOM results to the enhanced ability for the system to maintain stability as well as remain in synchronism. Particularly, the combination of STATCOM with PSS W Delta will assure short transition duration (4s), degree of deviation angle (d_thetal1_2) is small $\left(52.9^{0}\right)$.

\section{CONCLUSION}

In this study, the power system stability enhancement via
PSS and SVC, STATCOM stabilizer when applied independently and also through coordinated application was discussed and investigated. PSS_SVC, PSS_STATCOM stabilizer provides great damping characteristics and enhance significantly the system stability compared to individual design of these stabilizers.

\section{REFERENCES}

[1] R. I. Kamwa, L. Soulieres, J. Potvin, and R. C. Grondin, "An approach to PSS design for transient stability improvement through supplementary damping of the common low frequency," Augest 1993.

[2] Y. N. Yu, Electric power system dynamics, New York: Academic Press, 1983.

[3] P. W. Sauer and M. A. Pai, Power system dynamics and stability, Englewood Cliffs, NJ, USA: Prentice-Hall; 1998.

[4] A. E. Hammad, "Analysis of power system stability enhancement by static VAR compensators," IEEE Trans PWRS, vol. 1, no. 4, pp. 222227, 1986.

[5] A. R. Mahran, B. W. Hogg, and M. L. El-Sayed, "Coordinated control of synchronous generator excitation and static VAR compensator," IEEE Trans Energy Conv, vol. 7, pp. 615-22, 1992.

[6] A. Rahim and S. Nassimi, "Synchronous generator damping enhancement through coordinated control of exciter and SVC". IEE Proc Gener Transm Distrib, vol. 143, no. 2, pp. 211-218, 1996.

[7] M. Noroozian and G. Anderson, "Damping of power system oscillations by use of controllable components," IEEE Trans PWRD, vol. 9, no. 4, pp.2046-2054, 1994.

[8] H. F. Wang and F. J. Swift, "A unified model for the analysis of FACTS devices in damping power system oscillations. Part I. Singlemachine infinite-bus power systems," IEEE Trans PWRD, vol. 12, no. 2, pp. 941-946, 1997.

[9] Y. Y. Hsu and C. L. Chen, "Identification of optimum location for tabilizer applications using participation factors," IEEE Proc., Part C vol. 134, no. 3, pp. 238-244, 1987.

[10] M. S. El-Moursi and B. Bak-Jensen, "Novel STATCOM controller for mitigating SSR and damping power system oscillations in a series compensated wind park," IEEE Trans on Power Electronics, 2010.

[11] IEEE recommended practice for excitation system models for power system stability studies, IEEE St. 421.5-2002.

[12] P. Kundur, McGraw-Hill, 1994, ch. Section 12.5.

[13] M. Klein, G. J. Rogers, and M. S. Zywno, and P. Kundur, IEEE Trans. PWRS4, May 1989, pp. 614-626.

[14] M. Klein, G. J. Rogers, and P. Kundur, "A Fundamental Study of Inter-Area Oscillations," IEEE Trans, Power Systems Volume- 6, Number-3, August 1991. pp 914-921.

[15] P. Jiang, W. J. Yan, and W. Gu, "PSS Parameter Optimization with Genetic Algorithms,” DRPT 2008, Nanjing China, 6-9 April 2008, pp. 900-903.

[16] M. J. Gibbard, D. J. Vowles, and P. Pourbeik, "Interactions between, and effectiveness of, Power System Stabilizers and FACTS Device Stabilizers in Multimachine Systems," IEEE Trans. on Power Systems, vol. 15, May 2000, pp. 748-755.

[17] N. Martins, L. T. G. Lima, "Determination of Suitable Locations for Power System Stabilizers and Static VAR Compensators for Damping Electromechanical Oscillations in Large Scale Power System," IEEE Trans. on Power Systems, vol. 5, no. 4, pp. 14551469,1990 .

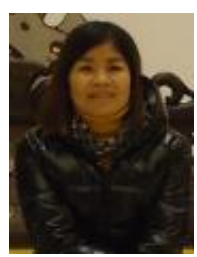

Tran Thi Ngoat was born in Hung Yen, Vietnam, on February 03, 1978. Currently, she is a Ph.D. Student of Wuhan University, School of Electrical Engineering, Her main research interests are power electronics technology application and power quality control.

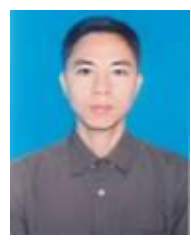

Le Ngoc Giang was born in Hanoi, Vietnam, on July 21, 1975. Currently, he is a Ph.D. Student of Wuhan University, School of Electrical Engineering, His main research interests are power system control and power system stability analysis. 